Article

\title{
Pressure-Point Strategy: Leverages for Urban Systemic Transformation
}

\author{
Katleen De Flander ${ }^{1, *}$ and Jeb Brugmann ${ }^{2}$ \\ 1 IASS Institute for Advanced Sustainability Studies Potsdam, Berliner Strasse 130, Potsdam 14467, Germany \\ 2 The Next Practice, 58 Ravina Crescent, Toronto, ON M4J 3M2, Canada; jeb.brugmann@thenextpractice.com \\ * Correspondence: katleen.de.flander@iass-potsdam.de; Tel.: +49-331-28822-346
}

Academic Editor: Tan Yigitcanlar

Received: 7 November 2016; Accepted: 9 January 2017; Published: 11 January 2017

\begin{abstract}
Sustainability can be understood as a specific kind of problem framing that emphasizes the interconnectedness of different problems and scales and calls for new forms of problem handling that are much more process-oriented, reflexive and iterative in nature. Closely related with the notion of reflexive governance, we propose such an alternative strategy for societal problem handling and change management in the urban context. The strategy starts from stress states in the urban system(s) and uses their initial momentum to encourage systemic change through intraventions-rather than interventions-at selected pressure points. This paper highlights the potential to evolve what has often been an intuitive practice, led by community or elected leaders with unique wisdom about functions and pressure points in their urban system, into a more accessible strategy for shaping socio-ecological transformation in urban practice.
\end{abstract}

Keywords: pressure points; urban; sustainability; transformation; reflexive governance; complexity

\section{Introduction}

In line with transition discourses that are based on complexity theory, Voss and Kemp [1,2] argue that sustainability, as the main second-order problem of modernist problem-solving, calls for new forms of problem handling and that these differ from the forms that are adequate for delimitable, decomposable problems that can be managed in a linear way. They suggest that if we understand sustainability as a specific kind of problem framing that emphasizes the interconnectedness of different problems and scales, then 'sustainable development is more about the organisation of processes than about particular outcomes' [2] (p. 4). This paper proposes such a strategy for complex problem handling and change management in the urban context. The result of such a strategy is a set of intraventions-rather than interventions—at selected 'pressure points', to facilitate desired systemic 'transformation' [3,4].

We follow Sassen [5] in her argument that our current global ecological conditions are not the result of urban agglomeration and density in itself but they are the results of the specific types of urban systems that we have developed. These infrastructures, and their related consumption patterns and management processes, have become institutionally globalised, reproducing relatively similar and even predictable environmental transitions in the worldwide process of urbanisation [6,7]. As with globalised production generally, urban systems today are scaled through widely standardised forms of technology, design, and business models, supported by globalised institutional arrangements in the arenas of regulation, finance, and governance [8-10]. These systems reproduce globalised patterns of consumption and lifestyle that are widely understood as being unsustainable for a growing human population. If we set out to tackle the (local and global, social and environmental) externalities of these urban systems and processes, then we will clearly have to go beyond efficiency strategies and move towards transformations in the production and renewal of urban places and systems. 
Such transformations, we argue, involve a shift from the scaling of standardised typologies and systems to the development of capacity for more customised urban development [11]. The question is 'where to start changing urban systems' [12] (p. 56), considering their planetary nature [13-16], their tensions among scales $[17,18]$ and their vested power relations $[19,20]$.

We learn from times and places of shock that people and systems are more flexible for change than we normally consider them to be. We also see that most innovations do not come from places of abundance and equilibrium but from the places where necessity ('the mother of invention') and low budgets demand new and sometimes radical interventions that go way beyond high-tech fixes. The latter are often sold as niche innovations but are more often co-opted experiments by the existing neoliberal system [21]. Klein [22], in addition, underlines that shock is commonly used as an "effective" strategy in neoliberal tactics. Based on this simple underlying idea that it is more difficult to affect significant change in a situation of relative comfort than in a situation where the current systems (including social and institutional systems) are under stress or in decay [23], this strategy starts from stress states in the urban system(s). This active state of necessity produces the initial momentum for change in the system(s). Systemic change however, goes much further than only symptom relief. Pressure points are those places in the system(s), either directly or indirectly interconnected with the stress states, which are found to have the most potential to push the initial momentum in the desired direction through intravention. In't Veld [24] defines 'intraventions' as attempts to change real-world configurations from within, as opposed to interventions, which attempt to influence a system from outside. However, 'since any governing intervention into a system is necessarily part of that system and system boundaries can always be drawn wider' [25], we use the term intravention here to highlight the fact that the iterative process of locating and analysing the stress states in the urban system(s) and designing the set of intraventions is a process that should be strongly based on local knowledge, leadership and ingenuity. Referencing the evidence from documented cases and practices, this paper highlights the potential to evolve what has often been an intuitive practice, led by community or elected leaders with unique wisdom about functions and pressure points in their urban system, into a more accessible process strategy for shaping socio-ecological transformation in urban places.

The proposed Pressure-Point Strategy leans closely towards the notion of 'reflexive governance', the strategy elements and procedural requirements of which provide a useful framework for it. Reflexive governance refers to the problem of shaping societal development in the light of the reflexivity of steering strategies and 'acknowledges that governing activities are entangled in wider societal feedback loops that are partly shaped by the (side-)effects of its own working' [1] (p. 4). At the same time, the focus on stress states and intraventions in pressure points answers to the critique of Karvonen et al. [21] (p. 114), who state that, to date, 'urban experiments [ ... ] have largely reinforced rather than reoriented existing power geometries [... ] and on the whole exhibit the paradoxical qualities of promising radical change while practicing business as usual', by proposing that experiments initiated at times and places of stress have more potential for systemic change (in one direction or another).

After giving a short background on the use of pressure points as an intuitive practice, we present a framework of elements that underlie a methodological approach of such a practice, followed by the introduction of the strategy itself with its three consecutive steps: identifying, understanding and designing. We discuss a practical retrospective case from Chicago to illustrate the method and end with a discussion.

\section{From Intuitive Practice to Strategy}

The idea of finding and beginning a process of change through identified pressure points has been used, often intuitively, in many locations and settings throughout the world. Excellent leadership, deep local knowledge and often a very low budget forced practitioners to focus limited resources on small opportunities that were ripe for intravention and change, and which would also carry maximum possible social, political and economic influence at larger urban scales and across the 
arenas of community organising, policy, planning, design, and public investment. For instance, the former mayor of Curitiba, Brazil, Jaime Lerner, has been a leading practitioner of a pressure point approach, which he has described as 'urban acupuncture' [26]. Lerner's approach involved the selection and orchestration of site-specific intraventions to advance both civic understanding and material demonstration of new system-wide development concepts (e.g., the downtown pedestrian mall, BRT integration stations, flood plain land swapping, establishment of ethnic community cultural facilities and identities in public parks) within the context of limited means. Lerner argues that tackling urban problems at appropriate pressure points can cause a positive ripple effect throughout entire communities. 'Sometimes urban planning is too slow', he states, 'The idea is to create energy' [26]. One well-known intravention involved the night-time demolition of a block of downtown roadway to establish the first demonstration of the city's central pedestrian mall. The stress state arose from chronic congestion of the main downtown avenue by cars and private bus operators (often in violation of their concession terms) and the status quo auto-focused demands of downtown commercial interests, on the one hand, and the municipality's strategy for transit-oriented growth and transformation of the bus concession regime on the other hand. In this instance, the intravention-a middle-of-the-night bulldozing of one block of the downtown avenue and its repavement as a pedestrian street-created evidence of the commercial potential of the new form of streetscape. It surfaced the public support for transformation and the political pressures both for and against it.

A second example is the transition of Barcelona's modernist typology of illes (i.e., blocks) into a new typological unit, the 'super-ille', joining nine urban traditional illes [27]. The source of disequilibrium was the increasing congestion of residential areas and their narrow streets and neighbourhood plazas (increasingly used for parking), along with changing residential demographics. The desired systemic outcome is to route cars around the neighbourhood illes and to re-establish pedestrian-friendly living at the neighbourhood scale, reinforcing traditional neighbourhood relations, uses of public space and commercial life. The introduction of the super-ille began with the first strategic project in the Ribera district following extensive neighbourhood discussions, upon which basis the physical design, traffic planning, and stakeholder engagement process for transitions in other districts could be understood and ultimately codified.

Such intraventions at local-scale pressure points are also a fundamental method in various community-organising traditions, be these the building occupations of squatters in central Europe, the neighbourhood-scale intraventions of community organisers who pushed for change in the face of entrenched political machines in the cities of the northeast and midwest United States (e.g., Chicago), the 1990s squatter movement in Berlin which surfaced the demand and need for affordable housing at a time when international investment was flooding into the city, or the 'Wächterhäuser' scheme in Leipzig [28].

These examples of pressure-point intraventions supported the emergence of new models of urban (re)development and thereby had impacts that reached far beyond a specific point in space. In the following section we discuss the strategic elements and steps of a more explicit process method, building upon the lessons from such successful cases.

\section{The Pressure-Point Approach}

Before introducing the three steps of the Pressure-Point Approach in more detail, we take a step back to discuss the strategic elements that lie at its basis.

\subsection{Strategic Elements}

The six strategic elements presented by Voss and Kemp [1,2], as criteria to evaluate the actual working of reflexive governance arrangements, apply to this approach. We touch upon several of them here in a contextualised manner and add elements that are more specific to this strategy. 
Local Process. The mapping of symptoms, their analysis, and the design of the intravention set to trigger transformation at pressure points should be executed by local people, drawing upon their local tacit knowledge and ingenuity.

Transition Brokers. A critical ingredient for urban change processes is 'transition brokers' (or 'change agents' as they are often called) $[29,30]$ such as Salvador Rueda (director and founder of the Barcelona Urban Ecology Agency, instigated the first super-illes project in Barcelona) or community organisers (referenced below) in Chicago. These are important community leaders (not necessarily public officials) who facilitate the transition process and the transfer and exchange of knowledge, using narratives to inspire and create co-responsibility and usually acting at multiple scales. The mapping, diagnostic and intravention processes will most definitely need the agency of such local transition brokers.

Iterative Nature of the Process. Urban change is itself a constant negotiation. The Pressure-Point Approach is a process that should be cycled through several times, taking into account the flux of urban reality, the high probability of unintended side-effects of the intravention set, changing values and perceptions and feedback loops.

Time Factor. One of the key notions of shock is 'time'. Openings for intravention are often bound by specific 'opportunity time frames', which can be very limited in length. This means that the mapping and diagnostics are in constant flux, linking back to the need for an iterative process strategy.

Opening up before Closing down. Responding to the efficacy paradox of reflexive governance, namely what Voss and Kemp [1] describe as the contradicting requirements of opening-up problem handling for conceptualisation (to adequately grasp the factual embedding of decision-making in complex contexts with heterogeneous values and distributed power) and closing-down for keeping up action capacity, this Pressure-Point Approach handles the sequential opening and closing as follows: the first two steps of identifying and understanding are meant to 'open up' the process to grasp the complexity, let the information flow openly, and understand interconnectedness, power relations, different viewpoints, layers and contradictions. Depending upon the degree of conflict manifest in the problem context, the opening-up process may be more or less explicit and open to broad public engagement. The third and 'intravention' step is the 'closing down' phase, necessary to be able to take coordinated action in the urban reality. In effect, such a process is typical of successful local leaders, who may spend years taking a broad 'reading' of the environment on which basis they may then make a strong, decided intravention at a critical window of opportunity. In a similar way, Stirling [31] pleads for more plural and conditional approaches before the actual decision-making process, arguing that when knowledge is uncertain, one should 'keep it complex' in order to see the range of perspectives and divergent interpretations for decision-making on complex and contested issues.

Set Guiding Direction. Once there is a sufficient level of understanding and a desire to intravene, the third step of designing the set of intraventions at selected pressure points will need to be preceded by a decision on the guiding direction in which change is pushed. This is the guiding direction for the alignment of the intraventions as we will introduce below.

\subsection{A Three-Step Iterative Process}

The Pressure-Point Approach is an iterative process which consists of the following three steps as visualised in Figure 1: (1) identifying stress states through symptom mapping; (2) understanding complexity through diagnostic mapping and symptom analysis; and (3) designing the intravention set at selected pressure points. In what follows, we go deeper into each of these steps. 


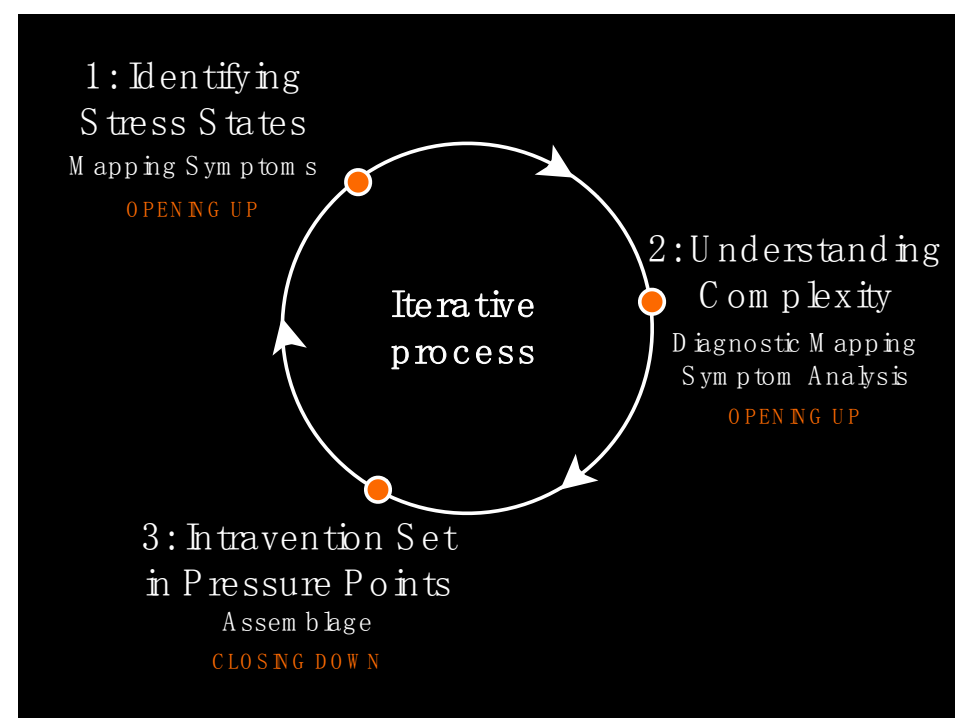

Figure 1. Pressure point approach—a three-step iterative process.

\subsection{Step 1: Identify Stress States-Empirical Symptom Mapping Section}

The first step is a straightforward mapping process of the symptoms of the complex problem. A symptom reflects the presence of an "unusual state" or "stress state" in the urban system, such as an area of concentrated air pollution or food security disturbances. This active state of necessity gives an initial momentum for change in the system. In practice, it is unlikely to find the necessary willingness and resources to tackle a complex problem in places where there is an overall state of equilibrium and comfort as a starting point, or even where vulnerabilities are considered to be high (e.g., the perceptions of downtown shop owners when considering pedestrianisation, as in Curitiba). Systemic change, however, goes much further than only symptom relief. We can identify several types of stress states:

- Need to Act: Active State of Necessity. There is risk in the current situation that requires change, either because of the potential loss of function or imposition of costs that will destabilize systems beyond the accepted limits of tolerance. The consequences of inaction are clear. Symptoms or stresses can be of a social, demographic, environmental, political, technical or economical nature or often a specific combination of these.

- Shock. In some cases this 'need to act' can come very sudden, as a shock. These 'breaking news' stress states can be of natural origin such as a hurricane, a flood or an earthquake (of course, human influence on, for instance, climate change could increase their frequency and intensity), or of manmade origin, such as the collapse of the financial system or the housing market, or an epidemic or an embargo (e.g., the well-known US embargo against Cuba). Note that systemic shocks can be interconnected.

- Latent Need to Act. There is fragility in the urban system that will exacerbate the impacts of a shock, 'it is just a matter of time' [32].

- Managed Creation of Stress or Socio-Political 'Heat'. This is basically self-induced stress, which represents a commonly used tactic to trigger action in the system, such as Lerner's bulldozing of the downtown avenue. Media can play an important role here.

\subsection{Step 2: Understand—Diagnostic Mapping and Symptom Analysis}

There are no easy linear causes or solutions to complex problems. A failure to recognise this often leads to unexpected feedbacks [33] (e.g., the well-known example of building traffic flyovers to solve a traffic problem, only leading to increased car use). This diagnostic step intends to prevent 
simplistic solutions for complex problems and seeks to unravel the interconnections, potential triggers, relations, interdependencies and forces at work that underlie the manifestation of the symptoms that were identified in step 1 . We propose the use of both diagnostic mapping and symptom analysis for this.

Diagnostic Mapping. Once the symptoms are mapped in step 1, diagnostic mapping seeks to visually reveal the underlying causes, flows and interconnections of the identified symptoms that have accumulated in specific urban systems. The function of mapping here is less to mirror reality than to reveal and realise the potential and triggers for change [34]. We are not mapping design or form but strategic dynamics, potential triggers and interconnections that can be leveraged later to advance a transition process. Depending on the landscape, the diagnostic mapping can go beyond the city's administrative borders in the extended urban systems. Whether specific intraventions will be able to influence these extended systems is not the question being explored at this stage. This is the stage of opening up in which we should accept complexity. Experts might identify different triggers or interconnections than community actors or public officials but these different interpretations are all respected items of the same map.

Symptom Analysis. In association with diagnostic mapping, symptom analysis seeks to analyse the forces in the particular symptom that are facilitating or restraining the momentum moving out of its stress state. Symptom analysis falls in the realm of 'momentum analysis'. Since a momentum is a vector quantity, it is described by both magnitude and direction. We can evaluate the following forces in the specific symptoms:

- Size of the net facilitating forces (for a given moment of time) that are increasing the momentum (moving away from the stress state).

- Size of the net hindering forces (for a given moment of time) that are restraining the momentum (from moving away from the stress state).

- Direction of the net forces and the ability for their alignment.

Figure 2 is a visualisation of a symptom analysis breaking down the different kinds of forces and attributing them a size and extent of direction. Note that this is a snapshot in time as the dynamics in a particular point in urban space are constantly changing. This step is still part of the 'opening up' phase. The analysis should be done in an open and descriptive way. It is all about describing the present situation.

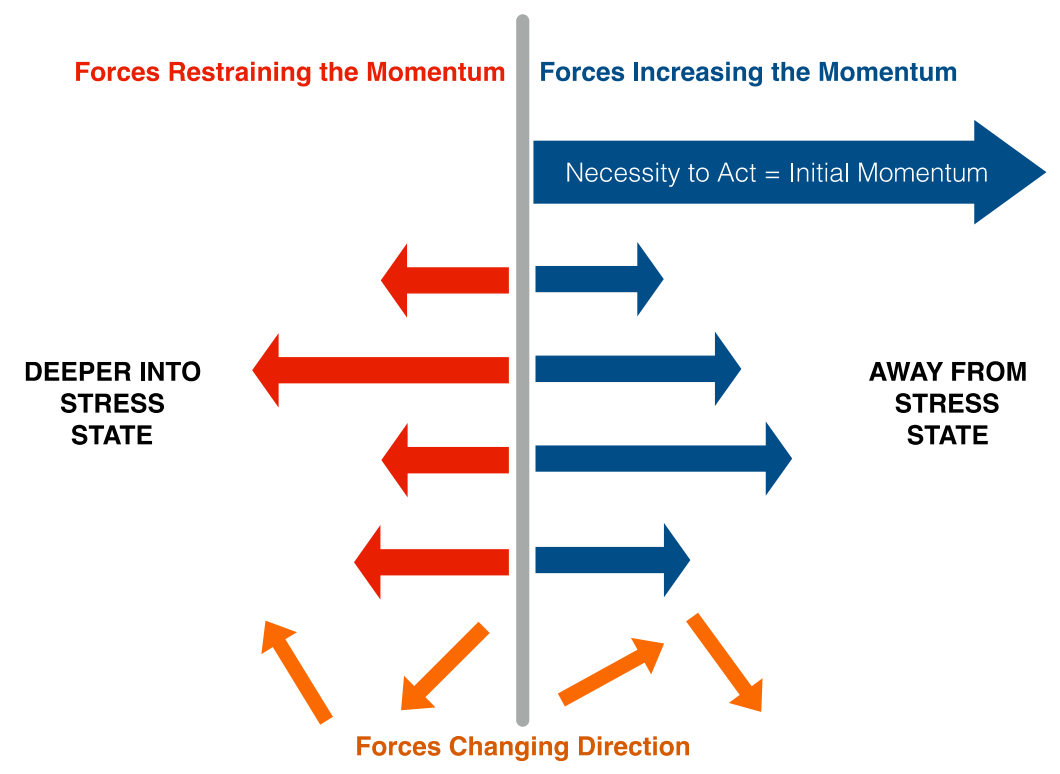

Figure 2. Symptom analysis (based on the force field analysis, originally created by the psychologist Kurt Lewin in the 1940s for use in social situations). 


\subsection{Step 3: Set Direction and Design the Intravention Set at Selected Pressure Points}

After 'keeping it complex' [31], having mapped and diagnosed the symptoms and analysed the interdependencies and the forces that are working within them, this third step is the moment where the strategy needs a 'closing-down' phase, necessary to allow for action to be taken in practice. On the basis of the diagnostic analysis in step 2, a joint decision to act or not, and in which direction to act, should be taken.

Pressure points are those places in the urban system(s), either directly or indirectly interconnected with the symptom(s), which are found to have the most potential to push the initial momentum in the desired direction through intravention. They are the points where you apply pressure (via intraventions) to relieve the stress state. Designing the set of intraventions is all about deciding where and how to instigate change in the system, amplify the useful and dampen the less useful forces, and align forces towards the chosen direction. Pressure points are thus used as leverages for pushing the momentum in the desired direction, and to release and steer energies from the existing stress.

A pressure-point intravention may be a single, bold measure, such the citizen occupation of a building. However, to affect a truly new momentum, an effective intravention is typically a designed set of actions meant to harvest, apply, direct, and align forces in one or several pressure points of an entire system to push in the desired direction. For instance, in the Curitiba case, the effectiveness of the intravention depended on the new streetscape design and the establishment of a '24-Hour Street' (a gallery with shops, bars and restaurants which was open $24 \mathrm{~h}$ ), which attracted people and created safety in the new pedestrian zone while addressing the business concerns of local commercial interests. One may therefore speak of an 'intravention set'. The intravention set has three key components (Figure 3):

A. Intraventions that create openings to weaken or by-pass the hindering forces towards the desired direction. The hindering forces, which are often systemic dependencies or vested power structures, are impeding systemic change. These hindering forces can be weakened or by-passed by creating openings (disruptions) in the current systems to make space for alternative systems to develop and ideally outcompete the old system.

B. Intraventions that strengthen or add facilitating forces that increase the momentum towards the desired direction.

C. Align the pressure point intraventions collectively towards the desired direction. The openings and forces of the intravention set should be aligned in such a way that they reinforce each other and do not adversely affect each other.

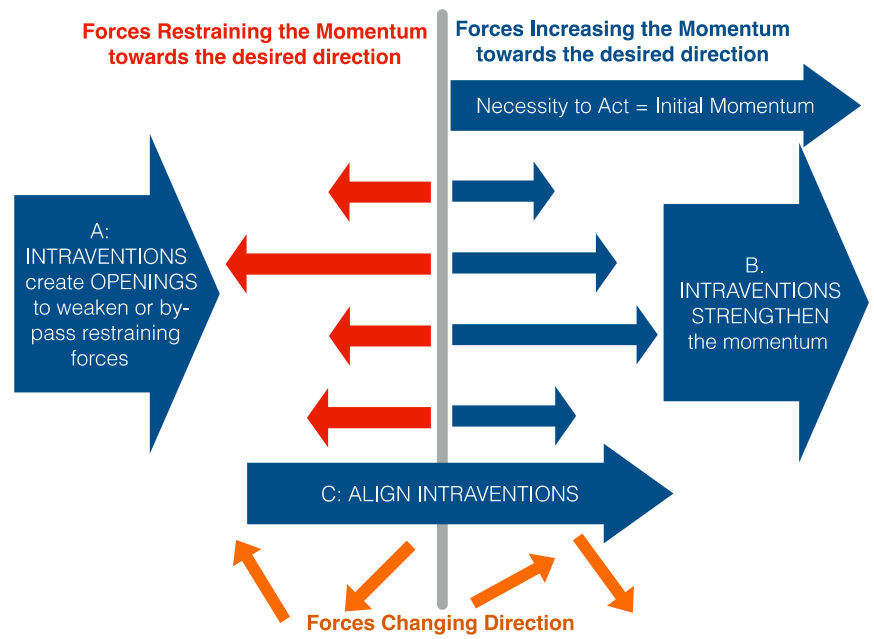

Figure 3. The three components of the intravention set. 
An intravention thus does not necessarily need to be a 'project'; it can just as well be 'taking away' something (e.g., taking away $3 \%$ of parking places per year in Copenhagen [35]), 'facilitating' something that was not possible before or 'consequently changing priorities' from the existing to an alternative system.

Questions that can guide actors to conceptualize and design intravention sets are: What is the balance of losers/winners of this intravention set? How would the intravention set affect the power relations in its context and would it create openings for new alignment or alliances? Can we foresee externalities of the intravention set? Would there be a demonstration value? We have to accept that it is impossible to predict the exact outcomes of an intravention set as there will always be unintended consequences and unexpected side-effects. These should be evaluated and taken up in the next round of the iterative process.

\section{A Case Example: Neighbourhood Regeneration in Chicago}

This section discusses the mix of measures that kick-started the regeneration in Chicago's Edgewater neighbourhood in the 1980s and provides a fascinating, retrospective example of the use of stress states and the discovery and consolidation of pressure-point intraventions.

\subsection{The Local Context}

The Great Depression and then all-out production for the Second World War left post-War Chicago with a base of early 20th century infrastructure, plants and equipment that could not compete in the late 20th century. Between 1965 and 2000, Chicago lost 70\% of its manufacturing jobs to newly built suburban areas. Chicago's residents followed. Between 1960 and 1990, Chicago's population dropped by almost 800,000 people, gutting the city's mixed-use residential/industrial/commercial neighbourhoods [36].

Adding to the momentum of decline, over the course of two decades, four business models stripped the remaining value from neighbourhood buildings. Predatory finance for home mortgages on inner city properties filled the void of regulated bank finance, driving inner city households further into poverty. Then local real estate agents used 'blockbusting' racial scare tactics to secure properties at reduced prices from fleeing white households and then sell them at a premium price to African American households. The resulting high rates of loan defaults and tax delinquency created openings for slum lords to secure properties at minimal prices in foreclosure sales or city tax auctions. The slumlord's basic business model was to squeeze as much short-term cash rent as possible from a building, without making any capital investment in its maintenance. Finally, once a slum building was all but uninhabitable, the slumlords hired arsonists to burn their building and collect on their fire insurance policies. Drug dealers inhabited abandoned buildings and took territorial control of cleared lots and unmaintained parks [36].

Together these models of stripping value from the city created a continuous cycle or momentum of decline. Chicago's unrivalled grassroots community organisers had to discover how to map and read the emerging stress, triggers and interconnections in this cycle of decline, how and where to intravene to stop the negative momentum, and how and where to create openings for alternative models of reinvestment.

\subsection{The Process}

In the formerly middle-class, European Edgewater neighbourhood in the north shore area of Chicago, one of the first actions taken by the new neighbourhood and block associations that formed in the late 1980s was detailed mapping of each building, park, and street corner under stress from the value-stripping disinvestment process and crime. An inventory was taken of every lot, park, and building - 300 buildings involving 10,000 units. A special focus was given to the corridor constituted by Kenmore and Winthrop Avenues, infamously known at the time as 'Arson Alley'. The mapping exercise (i.e., a broad-based 'opening-up process') documented ownership, occupancy, and each building 
and unit's status and underlying interconnections within the context of the above-described cycle of decline. The community associations then evaluated the remaining use-value in each building and lot (i.e., 'understanding complexity'), and developed a set of strategies and tactics (i.e., intraventions) for pursuing the renewal of that value and the regeneration of their neighbourhood. These strategies and tactics implicitly reflected a resident analysis of the facilitating and restraining forces at work in various systems and levels, and a careful selection of aligned points for intraventions to push the momentum towards their desired direction.

To trigger the transition process in the Edgewater neighbourhood, the local activists, as relatively new and poorly resourced change agents, implemented intraventions both simple and complex. One of these was to establish a neighbourhood source of funding for community planning that was independent of the infamous political machine of Mayor Richard Daley. They leveraged one of the new forces that was changing the direction of momentum in the American urban landscape: the establishment of federal government programs for community-based organizations and initiatives. The securing of this source of support, external to the existing local political-economic machine or regime, established a local planning capacity that ultimately resulted in the Edgewater neighbourhood establishing its own Planning and Zoning Committee. Today, that committee still previews development proposals prior to consideration by the respective, official city council committee.

With their mapping exercise they identified and made intraventions, at first around specific buildings, proactively recruiting new owners for buildings and training them to manage the buildings according to their plans and objectives. In some of the more troubled parks and street corners, they took direct intravening action to pressure the police to intervene. For instance, when neighbourhood activist Mary Ann Smith was first elected to the city council, she took to setting up a lawn chair and sitting at notoriously dangerous locations and called the police while sitting there to let them know. This triggered discussions with the police to schedule more regular patrols of these areas, and to make arrests.

Eventually, the model of new building ownership recruitment and training was institutionalized as a city-wide process through the establishment of the Chicago Community Investment Corporation (CIC). In other words, the initial tactical intraventions tested a foundation of practices for a new city-wide strategic process.

It is to be highlighted that the intraventions to increase positive momentum in the neighbourhood (i.e., for the most part by strengthening the capacity and know-how of local associations) were matched with intraventions to weaken the power of hindering forces (i.e., by securing funds that were independent of City Hall, and by recruiting and financially aiding alternative owners and political powers in the neighbourhood).

The above, initial intravention set formed part of a growing number of similar strategies in other stress areas across the city at the neighbourhood scale. These were then steadily scaled up citywide, initially through grassroots transfer from one block or from one neighbourhood to another. Ultimately, they were merged into a new body of practices for urban regeneration at a great scale, across the city, and finally embraced in the 1990s by the reform of Chicago's governing regime. As long-time activist and University of Chicago scholar Terry Nichols Clark put it, 'Few governments have changed as deeply and as rapidly as Chicago's-without a visible or violent revolution.' Chicago politics between the 1970s and 1990s have 'been revolutionized in many similar respects to the revolutions in Eastern Europe, Latin America and Asia' during the same years [11], [37] (p. 2).

This case example [36] is based on in-depth interviews undertaken in 1988 and 2008 by Jeb Brugmann, including: Lee Botts, Alliance for Great Lakes (2008); Walter Burnett, Alderman, City of Chicago (2008); Gail Cincotta, National People's Action (1988); Prof. Terry Clark, University of Chicago (2008); Forrest Claypool, Cook County Commissioner (2008); Mayor Richard Daley (2008); Dave Doig, Park National Bank (2008); Prof. Paul Greene, Roosevelt University (2008); Greg Harris, State Representative, State of Illinois (2008); Jack Markowski, Community Investment Corporation 
(2008); John McCarron, Chicago Tribune (2008); David Orr, Alderman, City of Chicago and Clerk, Cook County (1988); Mary Ann Smith, Alderman, City of Chicago (2008).

\section{Discussion}

This paper outlines a method for complex problem handling based upon what has heretofore been an intuitive process used by successful city leaders. The method focuses on explicit mapping of symptoms in urban system(s). An analysis of those stress states is then undertaken to inform the design of an intravention set at selected pressure points for the desirable transformation of systemic functions, uses and dynamics. Practitioners, from city planners to community activists, will likely agree with the simple underlying idea of this strategy, namely that it is easier to start change in places that are confronted by a range of accumulated stresses than in places where the system is in a stable equilibrium (even if there is a consciousness in the latter that this system has obvious environmental and societal externalities). Therefore, for people dealing with complex urban problems, this approach can be a useful tool (for both top-down and bottom-up initiatives) to instigate systemic change.

The question as to 'who' uses this approach and who decides on the direction in which change is to be steered is a contested one. Societal discourse on sustainability has highlighted the ambiguity of social goals and, at the same time, sustainability itself is a moving target [1,2]. We propose a process with strong input of local knowledge and leadership throughout the three steps but we are aware that every transformation process includes a struggle over power and opportunistic behaviour with the danger of the process being co-opted or dominated by the views and interests of the most powerful actors.

Typically, the development of specific pressure-point intraventions to reinforce momentum and to create new openings for desired change is a process of trial and error, as it is not certain how 'the system' will respond to each intravention or set. This brings us to the difficult question of the possibility of 'upscaling' a successful intravention set to other places or systems. As we argued, urban systems today are scaled through widely standardised forms of technology, design, and business models, supported by institutional arrangements in the arenas of regulation, finance, and governance. The strategic premise underlying this article is that fundamental changes in sustainability outcomes require the development of capacity for more customised urban development. The pressure-point approach is proposed to support the customisation of problem handling to a specific context. We do envision that the resulting intravention set could have a high demonstration value and could trigger pressure and learning in other places or communities.

However, uncertainty is intrinsic to this approach and we argue hereby for an increased tolerance for failure, which overrules the current trend of best-practice imitation. A culture of trying and failing should become part of urban change management together with a stronger trust in local ingenuity and phronesis. The art of urban 'acupuncture' is still little developed and most certainly has its limits. The cases we have used are retrospective and not based on its application specifically. Therefore, further investigation should focus on the practical testing and evaluating of this approach in different contexts and with different types of stress states, which will also bring forward its limitations more clearly.

\section{Conclusions}

Based on the urgency to deal with the wicked problems of our era, this paper has developed a strategy for transforming complex urban systems based on the potential leverages of shock and necessity. While there is an emerging academic interest in 'urban experiments' and 'living labs', they are at the same time being criticised for largely reinforcing rather than reorienting existing power geometries. Similarly, high-tech fixes are often sold as niche innovations but are more often co-opted experiments by the existing neo-liberal system. We welcome the move to a context-based and customised approach, but argue for a need to go back to heuristics. Most innovations do not come from places of abundance and equilibrium but from the places where necessity ('the mother of invention') and low budgets demand new and sometimes radical interventions that go way beyond 
high-tech fixes. The energy needed to leverage the transformation towards the widely shared vision of sustainability will come from the political power from underneath, from the slums and from crises, which will force us to adapt. Thus, we suggest consciously leveraging the momentum and energy that times and places of stress create to move towards transformations in the production and renewal of urban places and systems.

Acknowledgments: The authors thank Kathrine Brekke, Andreas Brück, Galina Churkina, Klaus Hoppe, Kate Houghton, Arun Jain, Stephen Kovats, Holger Kuhle, Hans Mönninghof, Manuel Rivera, Ania Rok, Ronald Rovers and Matt Watson for their participation in the IASS Transdisciplinary Expert Workshop: "Urban Pressure-Point Method" (November 2014). The Expert Workshop and its debates formed part of the methodology to test our strategy with practical experience, tacit knowledge and theoretical rigour and were therefore a valuable source for the further development of our Pressure-Point approach. We are grateful to the IASS for hosting this Expert Workshop and for covering the costs to publish in open access.

Author Contributions: Both authors jointly developed the Pressure-Point Strategy in a working paper and hosted an expert workshop at the IASS Potsdam (November 2014) to critically discuss the approach with a number of experts from both academia and practice, which led to new insights and the further development of the working paper. Katleen De Flander transformed the working paper into a scientific paper and brought in additional theoretical framings. Jeb Brugmann brought in most cases from practice, and specifically the Chicago case.

Conflicts of Interest: The authors declare no conflict of interest.

\section{References}

1. Voss, J.-P.; Kemp, R. Reflexive Governance for Sustainable Development-Incorporating feedback in social problem solving. In Proceedings of the ESEE Conference, Lisbon, Portugal, 14-17 June 2005; pp. 1-31.

2. Voss, J.-P.; Kemp, R. Sustainability and reflexive governance: Introduction. In Reflexive Governance for Sustainable Development; Bauknecht, D., Voss, J.-P., Kemp, R., Eds.; Edward Elgar Publishing Limited: Cheltenham, UK, 2006; pp. 3-28.

3. Brand, U. "Transformation" as a New Critical Orthodoxy: The Strategic Use of the Term "Transformation" Does Not Prevent Multiple Crises. Ecol. Perspect. Sci. Soc. 2016, 25, 23-27. [CrossRef]

4. Brand, U.; Brunnengräber, A.; Andresen, S.; Driessen, P.; Haberl, H.; Hausknost, D.; Helgenberger, S.; Hollaender, K.; Læssøe, J.; Oberthür, S.; et al. Debating Transformation in Multiple Crises. In World Social Science Report 2013: Changing Global Environments; Paris/Unesco Publishing: Paris, France, 2013; pp. 480-484.

5. Sassen, S. Cities are at the center of our environmental future. Surv. Perspect. Integrating Environ. Soc. 2010, 2, 1-8.

6. Marcotullio, P.; McGranahan, G. Scaling the Urban Environmental Challenge. In Scaling Urban Environmental Challenges: From Local to Global and Back; Marcotullio, P., McGranahan, G., Eds.; Routledge: London, UK, 2007; pp. 1-17.

7. Brugmann, J. Locating the 'Local Agenda': Preserving Public Interest in the Evolving Urban World. In Scaling Urban Environmental Challenges: From Local to Global and Back; Marcotullio, P., McGranahan, G., Eds.; Routledge: London, UK, 2007; pp. 331-354.

8. Beck, U. Power in the Global Age: A New Global Political Economy; Cross, K., Translator; Polity Press: Cambridge, UK, 2005.

9. Sassen, S. Spatialities and temporalities of the global: Elements for a theorization. Public Cult. 2000, 12, $215-312$. [CrossRef]

10. Sassen, S. Territory, Authority, Rights: From Medieval to Global Assemblages; Princeton University Press: Princeton, NJ, USA, 2006.

11. Brugmann, J. Welcome to the Urban Revolution: How Cities Are Changing the World; Penguin Group: Toronto, ON, Canada, 2009.

12. De Flander, K. Closed Cycles-Open City. In The Urban Climate Challenge. Rethinking the Role of Cities in the Global Climate Regime; Johnson, C., Toly, N., Schroeder, H., Eds.; Routledge: New York, NY, USA, 2015; pp. 37-59.

13. Brenner, N. Theses on Urbanization. Public Cult. 2013, 25, 85-114. [CrossRef]

14. Brenner, N.; Schmid, C. Planetary Urbanization. In Urban Constellations; Gandy, M., Ed.; JOVIS Verlag GmbH: Berlin, Germany, 2011; pp. 10-13.

15. Brenner, N.; Schmid, C. The 'Urban Age' in Question. Int. J. Urban Reg. Res. 2014, 38, 731-755. [CrossRef]

16. Brenner, N.; Schmid, C. Towards a New Epistemology of the Urban? City 2015, 19, 152-182. [CrossRef] 
17. Sassen, S. Bridging the Ecologies of Cities and of Nature. In Proceedings of the 4th International Conference of the International Forum on Urbanism: The New Urban Question-Urbansim beyond Neo-Liberalism, Amsterdam, The Netherlands, 26-28 November 2009; pp. 45-52.

18. Bai, X.; McAllister, R.; Beaty, M.; Taylor, B. Urban Policy and governance in a global environment: Complex systems, scale mismatches and public participation. Curr. Opin. Environ. Sustain. 2010, 2, 129-135. [CrossRef]

19. Foucault, M. The Subject and Power. Crit. Inq. 1982, 8, 777-795. [CrossRef]

20. Allen, J. Powerful City Networks: More than Connections, Less than Domination and Control. Urban Stud. 2010, 47, 2895-2911. [CrossRef]

21. Karvonen, A.; Evans, J.; van Heur, B. The Politics of Urban Experiments. Radical change or business as usual? In After Sustainable Cities; Hodson, M., Marvin, S., Eds.; Routledge: Abingdon, UK; New York, NY, USA, 2014; pp. 104-115.

22. Klein, N. The Shock Doctrine; Metropolitan Books: New York, NY, USA, 2008; pp. 1-565.

23. De Flander, K. Resource-Centered Cities and the Opportunity of Shrinkage. In Mitigating Climate Change: The Emerging Face of Modern Cities; Khare, A., Beckman, T., Eds.; Springer: Berlin/Heidelberg, Germany, 2013; pp. 45-57.

24. In't Veld, R.J. Transgovernance; IASS Institute for Advanced Sustainability Studies: Potsdam, Germany, 2011; pp. 1-134.

25. Watson, M.; University of Sheffield, Sheffield, UK. Personal communication, 2014.

26. Lerner, J. Acupunctura Urbana; Editora Record: Rio de Janeiro, Brazil, 2003.

27. Agència de Ecología Urbana de Barcelona. Supermanzana. CIUDAD Sosten. 2012, 11, 30-35.

28. HausHalten e.V. Wächterhäuser-Das Modell. Available online: www.haushalten.org (accessed on 6 March 2016).

29. Appadurai, A. Modernity at Large: Cultural Dimensions of Globalization (Public Worlds, V. 1); University of Minnesota Press: Minneapolis, MN, USA, 1996.

30. Escobar, A. Other Worlds Are (Already) Possible. Self-Organization, Complexity, and Post-Capitalist Cultures. In The World Social Forum: Challenging Empires, 2nd ed.; Sen, J., Waterman, P., Eds.; Black Rose Books: Montréal, QC, Canada, 2008; pp. 393-404.

31. Stirling, A. Keep it complex. Nature 2010, 468, 1029-1031. [CrossRef] [PubMed]

32. Taleb, N.N. Antifragile: Things that Gain from Disorder; Random House: New York, NY, USA, 2012.

33. Sanders, I. Complex Systems Thinking and New Urbanism. In New Urbanism and Beyond: Designing Cities for the Future; Haas, T., Ed.; Rizzoli: New York, NY, USA, 2008; pp. 275-279.

34. Corner, J. The Agency of Mapping: Speculation, Critique and Invention. In Mappings; Cosgrove, D., Ed.; Reaktion Books: London, UK, 1999; pp. 231-252.

35. Gehl, J.; Gemzøe, L. Public Spaces Public Life-Copenhagen; The Danish Architectural Press: Copenhagen, Denmark, 2004.

36. Brugmann, J. Governing the Entrepreneurial City: Local Markets and the Resurgence of Chicago. In Welcome to the Urban Revolution: How Cities Are Changing the World; Penguin Group: Toronto, ON, Canada, 2009; pp. 250-272.

37. Clark, T. Trees and Real Violins: Building Post-Industrial Chicago. Unpublished work, 2000.

(C) 2017 by the authors; licensee MDPI, Basel, Switzerland. This article is an open access article distributed under the terms and conditions of the Creative Commons Attribution (CC-BY) license (http:/ / creativecommons.org/licenses/by/4.0/). 